\title{
On Moving the Eyes to Flag Lucid Dreaming
}

\author{
Sergio Arthuro Mota-Rolim* \\ Brain Institute, Department of Physiology and Behavior, and Onofre Lopes University Hospital - Federal University of Rio \\ Grande Do Norte, Natal, Brazil
}

Keywords: Lucid dream, REM (Rapid Eye Movement) sleep, scanning hypothesis, eye movement, dream imagery

\section{INTRODUCTION}

Lucid dreaming (LD) started to be scientifically investigated through instructing dreamers to move their eyes as soon as they become lucid (Hearne, 1978; LaBerge et al., 1981). LD signaling through pre-agreed eye movements (PAEM) is possible because eye muscles are exempt from the muscular atonia that accompanies REM sleep (Aserinsky and Kleitman, 1953; Jouvet, 1962). In addition, it is hypothesized that eye movements during REM sleep relate to dreaming imagery (Roffwarg et al., 1962); however, studies that compared the direction of eye movements with dream recall yielded inconsistent results (for review see Arnulf, 2011). Moreover, it is not yet clear whether it is physiologically possible to move the eyes consciously and voluntarily during a pure REM sleep episode, as required for the PAEM. Consistently, it was found that frontal gamma activity $(\sim 40 \mathrm{~Hz})$ increases during LD, suggesting that LD is a mixture of REM sleep and waking (Mota-Rolim et al., 2008; Voss et al., 2009). Besides, alpha bursts ( 10 Hz) were preliminary observed during some

\section{OPEN ACCESS}

Edited by:

Luis de Lecea,

Stanford University, United States

Reviewed by:

Sushil K. Jha,

Jawaharlal Nehru University, India Michelle Claire Dumoulin Bridi, Johns Hopkins University,

United States

${ }^{*}$ Correspondence: Sergio Arthuro Mota-Rolim sergioarthuro@neuro.ufrn.br

Specialty section

This article was submitted to Sleep and Circadian Rhythms,

a section of the journal

Frontiers in Neuroscience

Received: 11 December 2019 Accepted: 24 March 2020 Published: 15 April 2020

Citation:

Mota-Rolim SA (2020) On Moving the

Eyes to Flag Lucid Dreaming.

Front. Neurosci. 14:361.

doi: 10.3389/fnins.2020.00361
PAEM (Mota-Rolim, 2012), which suggests that, in these cases, the PAEM may be performed in a transition from REM sleep to waking. Finally, despite being the most used technique to record LD, there is still no consensus regarding how to apply the PAEM in the lab. In this article, I will delve into the issues of recording LD through PAEM.

\section{THE SCANNING HYPOTHESIS}

The relation between eye movements during sleep and dreams was initially described by Aserinsky and Kleitman (1953), who observed that the sleeper eyes sometimes moved "rapidly, jerky, and binocularly symmetrical." These pioneer researchers also found that upon waking up sleepers during this period-named "rapid eye movement sleep," or "REM sleep" - most of them report dreams with intense visual imagery. Subsequently, in the first attempts to investigate the association between eye movements and dream imagery, it was observed a positive relation between the direction of rapid eye movements and gaze direction during the dream in $70-80 \%$, as reported following awakenings (Dement and Kleitman, 1957; Dement and Wolpert, 1958; Roffwarg et al., 1962). These results gave rise to the "scanning hypothesis" (Roffwarg et al., 1962), which postulates that the eye movements during sleep are directed by the dream imagery, in a comparable way as during the waking state, in which the eyes move toward scanned objects (for comprehensive reviews, see Arnulf, 2011; and Hong et al., 2018). Based on these findings, and on the fact that during REM sleep the limb-but not eye-muscles are atonic, Hearne (1978) and LaBerge et al. (1981) developed the PAEM technique aiming to objectively record LD in the laboratory.

\section{Studies that Corroborate the Scanning Hypothesis Physiological Conditions}

After the first studies that gave rise to the scanning hypothesis (Dement and Kleitman, 1957; Dement and Wolpert, 1958; Roffwarg et al., 1962), it was found a positive relationship between 
gaze direction subjectively experienced during LD and the actual eye gazes objectively measured (Tholey, 1983). A subsequent study investigating non-LD found similar results (Herman et al., 1984). More recently, LaBerge et al. (2018) reported that the eye movements during tracking of a target during lucid REM sleep are similar to those of waking perception (sustained smooth pursuit) and different from those of visuomotor imagination (saccadic eye tracking). Since perceiving, imagining, and dreaming activate the same brain areas for a given sensory modality (Farah, 1988; Ishai and Sagi, 1995; O’Craven and Kanwisher, 2000; Siclari et al., 2017), LaBerge et al. (2018) argued that during dreaming (but not during imaging) there are both low competition among sensory inputs and high activation in extrastriate visual cortices. Thus, the experience of image vividness is similar to waking perception and activates the primary pursuit temporal pathway that drives the related motor regions of the cerebellum (Krauzlis, 2004). LaBerge and colleagues also found that subjective eye gazes during LD are associated with corresponding rotations of the eyes, supporting the scanning hypothesis. However, not all rapid eye movements would track the dream imagery, thus they consider that there are multiple sources of eye movements in REM sleep, and only a fraction of them scans dream images.

According to Jouvet (1967), there is a close temporal relationship between the rapid eye movements and a phasic activity that starts in the pons, then propagates to the lateral geniculate nucleus until it reaches the occipital region. These ponto-geniculo-occipital (PGO) waves were first described in cats (Jouvet et al., 1959) but exist in other mammals including macaques and baboons (Datta, 1997). Interestingly, REM sleep amount (out of total sleep time) varies considerably among terrestrial mammals: approximately $56 \%$ in the platypus, $40 \%$ in ferrets, $23 \%$ in humans, $18 \%$ in cows, and $3 \%$ in the mongoose lemur (the lowest REM sleep amount of all) (Madan and Jha, 2012). In humans, Miyauchi et al. (2009) observed an activation of the primary visual cortex associated with the rapid eye movements, which suggests the existence of PGO waves in our specie, and a link between PGO spikes, rapid eye movements and the visual aspects of dreaming.

\section{Pathological Conditions}

Subjects with REM sleep behavior disorder have no muscle atonia during REM sleep, and their dream reports are congruent with the abnormal behaviors (Schenck et al., 1986). When their rapid eye movements accompany a goal-oriented behavior (e.g., climbing a ladder), $90 \%$ of the cases were related to their action (Leclair-Visonneau et al., 2010), which supports the scanning hypothesis.

\section{Studies That Do Not Corroborate the Scanning Hypothesis Physiological Conditions}

After the pioneer works that compared the direction of eye movements during REM sleep with gaze direction in the dream (Dement and Kleitman, 1957; Dement and Wolpert, 1958; Roffwarg et al., 1962), two studies yielded inconsistent results, with a concordance rate varying from 9 to $32 \%$, which was below chance (Moskowitz and Berger, 1969; Jacobs et al., 1972). In addition, some subjects awakened during phasic REM sleep (defined by rapid eye movement bursts) do not report dreaming (Siclari et al., 2013). Moreover, visual dreams are reported during both REM sleep with no rapid eye movements (tonic REM sleep) (Foulkes and Pope, 1973; Hobson et al., 2000; Hodoba et al., 2008) and non-REM sleep (Cavallero et al., 1992; Fosse et al., 2001; Mota-Rolim et al., 2015; Siclari et al., 2017). Additional studies in other animals also do not corroborate the scanning hypothesis. In monkeys, for example, Zhou and King (1997) found that some binocular rapid eye movements are not conjugated, that is, they do not move toward the same direction and thus lack a fixation point, which would prevent these eye movements to "watch" dream images.

\section{Pathological Conditions}

Despite the fact that congenitally blind individuals do not experience "visual" dreams and display rapid eye movements (Gross et al., 1965; Kerr et al., 1982), a recent work found that the frequency of their gazes is reduced and bears no relation with dream content (Christensen et al., 2019). In cats, when the visual cortex is removed the rapid eye movements are preserved (Jouvet, 1962), and the PGO waves, which may induce the formation of the images and other visual aspects of dreams, are generated simultaneously and in parallel with the rapid eye movements (Vanni-Mercier and Debilly, 1998).

\section{LUCID DREAMING AS A REM SLEEP TO WAKING TRANSITION}

In addition to the controversies surrounding the scanning hypothesis, it is unclear whether the eyes can be moved-in a voluntary and conscious way-within REM sleep, that is, without arousal or waking features. For example, the alpha rhythm power $(\sim 10 \mathrm{~Hz})$ increases during LD (Ogilvie et al., 1982; Tyson et al., 1984; Mota-Rolim et al., 2008), but alpha oscillations are associated with waking state with eyes closed (Berger, 1929; Adrian and Matthews, 1934). Similarly, frontal gamma power $(\sim 40 \mathrm{~Hz})$ increases during LD (Mota-Rolim et al., 2008; Voss et al., 2009), which suggests that LD is a mixture of REM sleep and waking consciousness. This supports the finding that the brain mechanisms that underlie the eye movements during sleep differ from those during wakefulness (Abe et al., 2008). In fact, frontal association areas control the eye movements during waking (together with other regions of the cingulate and parietal cortices) (Johnston and Everling, 2008), but during REM sleep these frontal areas are hypo-active (Maquet et al., 1996).

Furthermore, bursts of alpha activity during some PAEM were preliminary observed (Mota-Rolim, 2012). These alpha bursts occurring during REM sleep without muscle tone modification are classified as micro-arousals (Cantero and Atienza, 2000; Cantero et al., 2000). This suggests that, at least in some cases, the PAEM may be performed in a micro-arousal, i.e., a transitional phase from REM sleep to waking, and not within a pure REM sleep state. This may happen mainly for the naïve lucid dreamers-i.e., those who do not experience LD frequently, and who represent the vast majority of lucid dreamers. These subjects 
often report that they wake up as soon as they try to perform the PAEM, as if the required mental effort would induce a microawakening or a more superficial sleep. They also tend to wake up right after becoming lucid and have less control over the oneiric content (Mota-Rolim et al., 2013). On the other hand, Rak et al. (2015) found that narcoleptic patients-who experience fast transitions between waking and sleep-have more LD than the general population, and the mental effort needed to achieve and sustain a lucid REM sleep might be lower in these patients (Dodet et al., 2014). In a similar way, experienced lucid dreamers-a minority of people who have LD very often-have longer and more stable LD, as well as higher control over the dream content. In these people, LD may happen during a steady REM sleep state. Noteworthy, since recording LD is complex and costly, most sleep labs investigate experienced lucid dreamers, which increases the chance to successfully record an LD (but usually at the cost of small sample size). Besides, transferring these lab results to the general population (i.e., naïve lucid dreamers) should be done with caution.

\section{TOWARD A STANDARDIZATION OF THE PAEM}

The PAEM technique to flag LD during REM sleep has been widely used in physiological (LaBerge et al., 1981; Brylowski et al., 1989; Mota-Rolim et al., 2010; Dresler et al., 2012), pathological (Tang et al., 2006; Dodet et al., 2014; Oudiette et al., 2018), and artificial (Stumbrys et al., 2013; Mota-Rolim et al., 2019) conditions. Additionally, LD flagged by PAEM has also been described during non-REM sleep stages N1 (sleep onset) and N2 (superficial sleep) (LaBerge, 1980; Stumbrys and Erlacher, 2012; Mota-Rolim et al., 2015), but not during N3 (deep sleep).

Despite being the most used technique to record an LD, there is still not a consensus about how exactly PAEM should be applied, which resulted in several variations of the method, regarding mainly: (1) the number of eye movements, (2) the amount of series of eye movements, (3) the way these movements should be performed, and (4) when they should be performed. Below I detail each of these four points and suggest ways to standardize them for future studies.

1) The number of eye movements: Even though the involuntary eye movements of REM sleep being isolated, it is common to observe bursts of 2 to 5 consecutive eye movements (Arnulf, 2011). This happens especially in the elderly (Ficca et al., 1999), and resembles the PAEM. Thus, the minimum number of eye movements required to differentiate the voluntary ocular gazes from the involuntary ones that characterize REM sleep would be 6 (Mota-Rolim, 2012).

\section{REFERENCES}

Abe, T., Ogawa, K., Nittono, H., and Hori, T. (2008). Neural generators of brain potentials before rapid eye movements during human REM sleep: a study using sLORETA. Clin. Neurophysiol. 119, 2044-2053. doi: 10.1016/j.clinph.2008.05.008
2) Amount of series of eye movements: Dreamers could also be instructed to perform more than one series of PAEM, for example, the first series when they realize that they became lucid, and another series when they believe they are close to waking up. This would improve the technique, and consequently strengthen the reliability of the study.

3) How the eye movements should be performed: While most LD researchers instruct dreamers to shift their gaze laterally (Mota-Rolim et al., 2008; Voss et al., 2009; Dresler et al., 2012), others instruct to "scan the horizon" from left to right (Dodet et al., 2014). As a way to standardize the PAEM technique, LD researchers can follow the instructions suggested by Baird et al. (2019) (adapted from LaBerge et al., 2018), which require asking the dreamer to move the eyes all the way to the left and then to the right (as if looking at each of the ears) through a continuous movement without pausing.

4) When the eye movements should be performed: In addition to during dreaming, this technique could also be practiced during the waking state (with eyes open and closed) before starting the experiment, which constitutes a valuable opportunity for researchers to view the fingerprints of each individual and also provide feedback.

\section{CONCLUSIONS}

Despite some studies have found a relation between subjective eye movements that would scan the dream scenes and actual eyeball rotations during REM sleep, the scanning hypothesis is still controversial. More studies are also necessary to clarify whether the PAEM are realized during a pure REM sleep episode, or else mixed with (micro)-arousal/waking, especially in naïve lucid dreamers. Finally, since the PAEM constitute the most used method to scientifically study LD, a consensus on how to apply this technique in a standardized way is clearly warranted.

\section{AUTHOR CONTRIBUTIONS}

The author confirms being the sole contributor of this work and has approved it for publication.

\section{FUNDING}

This work was supported by Associação Mota-Rolim de Apoio as Artes e Ciências (AMORA).

\section{ACKNOWLEDGMENTS}

I thank Adriano Tort for helping me writing and reviewing the article, and AMORA for financial support.

Adrian, E. D., and Matthews, B. H. (1934). The interpretation of potential waves in the cortex. J. Physiol. 81, 440-471. doi: 10.1113/jphysiol.1934. sp003147

Arnulf, I. (2011). The 'scanning hypothesis' of rapid eye movements during REM sleep: a review of the evidence. Arch. Ital. Biol. 149, 367-382. doi: 10.4449/aib.v149i4.1246 
Aserinsky, E., and Kleitman, N. (1953). Regularly occurring periods of eye motility, and concomitant phenomena, during sleep. Science 118, 273-274. doi: 10.1126/science.118.3062.273

Baird, B., Mota-Rolim, S. A., and Dresler, M. (2019). The cognitive neuroscience of lucid dreaming. Neurosci. Biobehav. Rev. 100, 305-323. doi: 10.1016/j.neubiorev.2019.03.008

Berger, H. (1929). Über das Elektrenkephalogramm des Menschen. Arch. Psychiatr. Nervenkr. 87, 527-570. doi: 10.1007/BF01797193

Brylowski, A., Levitan, L., and LaBerge, S. (1989). H-reflex suppression and autonomic activation during lucid REM sleep: a case study. Sleep 12, 374-378. doi: 10.1093/sleep/12.4.374

Cantero, J. L., and Atienza, M. (2000). Alpha burst activity during human REM sleep: descriptive study and functional hypotheses. Clin. Neurophysiol. 111, 909-915. doi: 10.1016/S1388-2457(99)00318-1

Cantero, J. L., Atienza, M., and Salas, R. M. (2000). Spectral features of EEG alpha activity in human REM sleep: two variants with different functional roles? Sleep 23, 746-750. doi: 10.1093/sleep/23.6.1b

Cavallero, C., Cicogna, P., Natale, V., Occhionero, M., and Zito, A. (1992). Slow wave sleep dreaming. Sleep 15, 562-566. doi: 10.1093/sleep/15.6.562

Christensen, J. A. E., Aubin, S., Nielsen, T., Ptito, M., Kupers, R., and Jennum, P. (2019). Rapid eye movements are reduced in blind individuals. J. Sleep Res. 28:e12866. doi: 10.1111/jsr.12866

Datta, S. (1997). Cellular basis of pontine ponto-geniculo-occipital wave generation and modulation. Cell. Mol. Neurobiol. 17, 341-365. doi: 10.1023/A:1026398402985

Dement, W., and Kleitman, N. (1957). The relation of eye movements during sleep to dream activity: an objective method for the study of dreaming. J. Exp. Psychol. 53, 339-346. doi: 10.1037/h0048189

Dement, W., and Wolpert, E. (1958). The relation of eye movements, body motility, and external stimuli to dream content. J. Exp. Psychol. 55, 543-553. doi: $10.1037 /$ h0040031

Dodet, P., Chavez, M., Leu-Semenescu, S., Golmard, J., and Arnulf, I. (2014). Lucid dreaming in narcolepsy. Sleep 38, 487-497. doi: 10.5665/sleep.4516

Dresler, M., Wehrle, R., Spoormaker, V. I., Koch, S. P., Holsboer, F., Steiger, A., et al. (2012). Neural correlates of dream lucidity obtained from contrasting lucid versus non-lucid REM sleep: a combined EEG/fMRI case study. Sleep 35, 1017-1020. doi: 10.5665/sleep.1974

Farah, M. J. (1988). Is visual imagery really visual? Overlooked evidence from neuropsychology. Psychol. Rev. 95, 307-317. doi: 10.1037/0033-295X.95.3.307

Ficca, G., Gori, S., Ktonas, P., Quattrini, C., Trammell, J., and Salzarulo, P. (1999). The organization of rapid eye movement activity during rapid eye movement sleep is impaired in the elderly. Neurosci. Lett. 275, 219-221. doi: 10.1016/S0304-3940(99)00765-X

Fosse, R., Stickgold, R., and Hobson, J. A. (2001). Brain-mind states: reciprocal variation in thoughts and hallucinations. Psychol. Sci. 12, 30-36. doi: 10.1111/1467-9280.00306

Foulkes, D., and Pope, R. (1973). Primary visual experience and secondary cognitive elaboration in stage REM: a modest confirmation and an extension. Percept. Mot. Skills 37, 107-118. doi: 10.2466/pms.1973.37.1.107

Gross, J., Byrne, J., and Fisher, C. (1965). Eye movements during emergent stage 1 EEG in subjects with lifelong blindness. J. Nerv. Ment. Dis. 141, 365-370. doi: 10.1097/00005053-196509000-00014

Hearne, K. M. (1978). Lucid dreams: An elecro-physiological and psychological study (Doctoral dissertation). Liverpool University, Liverpool, United Kingdom.

Herman, J. H., Erman, M., Boys, R., Peiser, L., Taylor, M. E., and Roffwarg, H. P. (1984). Evidence for a directional correspondence between eye movements and dream imagery in REM sleep. Sleep 7, 52-63. doi: 10.1093/sleep/7.1.52

Hobson, J. A., Pace-Schott, E. F., and Stickgold, R. (2000). Dreaming and the brain: toward a cognitive neuroscience of conscious states. Behav. Brain Sci. 23, 793-842. doi: 10.1017/S0140525X00003976

Hodoba, D., Hrabri'c, K., Krmpoti'c, P., Breèi'c, P., KujundŽi'c-Tilja, M., and Majdanèi'c, Ž. (2008). Dream recall after night awakenings from tonic/phasic REM sleep. Coll. Antropol. 320, 69-73.

Hong, C. C.-H., Fallon, J. H., Friston, K. J., and Harris, J. C. (2018). Rapid eye movements in sleep furnish a unique probe into consciousness. Front. Psychol. 9:2087. doi: 10.3389/fpsyg.2018.02087

Ishai, A., and Sagi, D. (1995). Common mechanisms of visual imagery and perception. Science 268, 1772-1774. doi: 10.1126/science.7792605
Jacobs, L., Feldman, M., and Bender, M. B. (1972). Are the eye movements of dreaming sleep related to the visual images of the dreams? Psychophysiology 9, 393-401. doi: 10.1111/j.1469-8986.1972.tb01786.x

Johnston, K., and Everling, S. (2008). Neurophysiology and neuroanatomy of reflexive and voluntary saccades in non-human primates. Brain Cogn. 68, 271-283. doi: 10.1016/j.bandc.2008.08.017

Jouvet, M. (1962). Recherches sur les structures nerveuses et les mécanismes responsables des différentes phases du sommeil physiologique. Arch. Ital. Biol. $100,125-206$.

Jouvet, M. (1967). Neurophysiology of the states of sleep. Physiol. Rev. 47, 117-177. doi: 10.1152/physrev.1967.47.2.117

Jouvet, M., Michel, F., and Courjon, J. (1959). L'activite electrique du rhinencephale au cours dusommeil chez le chat. C.R. Soc. Biol. 153, 101-105.

Kerr, N. H., Foulkes, D., and Schmidt, M. (1982). The structure of laboratory dream reports in blind and sighted subjects. J. Nerv. Ment. Dis. 170, 286-294. doi: 10.1097/00005053-198205000-00006

Krauzlis, R. J. (2004). Recasting the smooth pursuit eye movement system. J. Neurophysiol. 91, 591-603. doi: 10.1152/jn.00801.2003

LaBerge, S. (1980). Lucid dreaming: An exploratory study of consciousness during sleep. (Doctoral dissertation). Stanford University, Stanford, CA, California.

LaBerge, S., Baird, B., and Zimbardo, P. G. (2018). Smooth tracking of visual targets distinguishes lucid REM sleep dreaming and waking perception from imagination. Nat. Comm. 9:3298. doi: 10.1038/s41467-01805547-0

LaBerge, S. P., Nagel, L. E., Dement, W. C., and Zarcone, V. P. (1981). Lucid dreaming verified by volitional communication during REM sleep. Percept. Mot. Skills 52, 727-732. doi: 10.2466/pms.1981.52.3.727

Leclair-Visonneau, L., Oudiette, D., Gaymard, B., Leu-Semenescu, S., and Arnulf, I. (2010). Do the eyes scan dream images during rapid eye movement sleep? Evidence from the rapid eye movement sleep behaviour disorder model. Brain 133, 1737-1746. doi: 10.1093/brain/awq110

Madan, V., and Jha, S. K. (2012). Sleep alterations in mammals: did aquatic conditions inhibit rapid eye movement sleep? Neurosci. Bull. 28, 746-758. doi: 10.1007/s12264-012-1285-8

Maquet, P., Peters, J., Aerts, J., Delfiore, G., Degueldre, C., Luxen, A., et al. (1996). Functional neuroanatomy of human rapid-eyemovement sleep and dreaming. Nature 383, 163-166. doi: 10.1038/ 383163a0

Miyauchi, S., Misaki, M., Kan, S., Fukunaga, T., and Koike, T. (2009). Human brain activity time-locked to rapid eye movements during REM sleep. Exp. Brain Res. 192, 657-667. doi: 10.1007/s00221-008-1579-2

Moskowitz, E., and Berger, R. J. (1969). Rapid eye movements and dream imagery: are they related? Nature 224, 613-614. doi: 10.1038/224613a0

Mota-Rolim, S., Pantoja, A., Pinheiro, R., Camilo, A., Barbosa, T., Hazboun, I., et al. (2008). Lucid Dream: Sleep Electroencephalographic Features and Behavioral Induction Methods. Búzios: First Congress IBRO/LARC of Neurosciences for Latin America; Caribbean and Iberian Peninsula.

Mota-Rolim, S. A. (2012). Epidemiological, cognitive-behavioral and neurophysiologic aspects of lucid dreaming (Doctoral dissertation). Federal University of Rio Grande do Norte, Natal, Brazil.

Mota-Rolim, S. A., Brandão, D. S., Andrade, K. C., de Queiroz, C. M. T., Araujo, J. F., de Araujo, D. B., et al. (2015). Neurophysiological features of lucid dreaming during N1 and N2 sleep stages: two case reports. Sleep Sci. 4:215. doi: 10.1016/j.slsci.2016.02.093

Mota-Rolim, S. A., Erlacher, D., Tort, A. B., Araujo, J. F., and Ribeiro, S. (2010). Different kinds of subjective experience during lucid dreaming may have different neural substrates. Int. J. Dream Res. 25, 550-557. doi: 10.11588/ijodr.2010.1.596

Mota-Rolim, S. A., Pavlou, A., Nascimento, G. C., Fontenele-Araujo, J., and Ribeiro S. (2019). Portable devices to induce lucid dreams-are they reliable? Front. Neurosci. 13:428. doi: 10.3389/fnins.2019.00428

Mota-Rolim, S. A., Targino, Z. H., Souza, B. C., Blanco, W., Araujo, J. F., and Ribeiro, S. (2013). Dream characteristics in a Brazilian sample: an online survey focusing on lucid dreaming. Front. Hum. Neurosci. 7:836. doi: 10.3389/fnhum.2013.00836

O'Craven, K. M., and Kanwisher, N. (2000). Mental imagery of faces and places activates corresponding stimulus-specific brain regions. J. Cogn. Neurosci. 12, 1013-1023. doi: 10.1162/08989290051137549 
Ogilvie, R. D., Hunt, H. T., Tyson, P. D., Lucescu, M. L., and Jeakins, D. B. (1982). Lucid dreaming and alpha activity: a preliminary report. Percept. Mot. Skills 55, 795-808. doi: 10.2466/pms.1982.55.3.795

Oudiette, D., Dodet, P., Ledard, N., Artru, E., Rachidi, I., Similowski, T., et al. (2018). REM sleep respiratory behaviours mental content in narcoleptic lucid dreamers. Sci. Rep. 8:2636. doi: 10.1038/s41598-018-21067-9

Rak, M., Beitinger, P., Steiger, A., Schredl, M., and Dresler, M. (2015). Increased lucid dreaming frequency in narcolepsy. Sleep 38, 787-792. doi: $10.5665 /$ sleep. 4676

Roffwarg, H. P., Dement, W. C., Muzio, J. N., and Fisher, C. (1962). Dream imagery: relationship to rapid eye movements of sleep. Arch. Gen. Psychiatry 7, 235-258. doi: 10.1001/archpsyc. 1962.01720040001001

Schenck, C. H., Bundlie, S. R., Ettinger, M. G., and Mahowald, M. W. (1986). Chronic behavioral disorders of human REM sleep: a new category of parasomnia. Sleep 9, 293-308. doi: 10.1093/sleep/9.2.293

Siclari, F., Baird, B., Perogamvros, L., Bernardi, G., LaRocque, J. J., Riedner, B., et al. (2017). The neural correlates of dreaming. Nat. Neurosci. 20, 872-878. doi: $10.1038 / \mathrm{nn} .4545$

Siclari, F., LaRocque, J., Postle, B., and Tononi, G. (2013). Assessing sleep consciousness within subjects using a serial awakening paradigm. Front. Psychol. 4:542. doi: 10.3389/fpsyg.2013.00542

Stumbrys, T., and Erlacher, D. (2012). Lucid dreaming during NREM sleep: Two case reports. Int. J. Dream Res. 5, 151-155. doi: 10.11588/ijodr.2012.2.9483

Stumbrys, T., Erlacher, D., and Schredl, M. (2013). Testing the involvement of the prefrontal cortex in lucid dreaming: a tDCS study. Conscious. Cogn. 22, 1214-1222. doi: 10.1016/j.concog.2013.08.005

Tang, H., Sharma, N., and Whyte, K. F. (2006). Lucid dreaming during multiple, sleep latency test. Sleep Med. 1:2. doi: 10.1016/j.sleep.2006.02.010
Tholey, P. (1983). Relation between dream content and eye movements tested by lucid dreams. Percept. Mot. Skills 56, 875-878.

Tyson, P. D., Ogilvie, R. D., and Hunt, H. T. (1984). Lucid, prelucid, and nonlucid dreams related to the amount of EEG alpha activity during REM sleep. Psychophysiology 21, 442-451. doi: 10.1111/j.1469-8986.1984. tb00224.x

Vanni-Mercier, G., and Debilly, G. (1998). A key role for the caudoventral pontine tegmentum in the simultaneous generation of eye saccades in bursts and associated ponto-geniculo-occipital waves during paradoxical sleep in the cat. Neuroscience 86, 571-585. doi: 10.1016/S0306-4522(98) 00045-1

Voss, U., Holzmann, R., Tuin, I., and Hobson, J. A. (2009). Lucid dreaming: a state of consciousness with features of both waking and non-lucid dreaming. Sleep 32, 1191-1200. doi: 10.1093/sleep/32.9.1191

Zhou, W., and King, W. M. (1997). Binocular eye movements not coordinated during REM sleep. Exp. Brain Res. 117, 153-151. doi: 10.1007/s002210 050209

Conflict of Interest: The author declares that the research was conducted in the absence of any commercial or financial relationships that could be construed as a potential conflict of interest.

Copyright $(\odot 2020$ Mota-Rolim. This is an open-access article distributed under the terms of the Creative Commons Attribution License (CC BY). The use, distribution or reproduction in other forums is permitted, provided the original author(s) and the copyright owner(s) are credited and that the original publication in this journal is cited, in accordance with accepted academic practice. No use, distribution or reproduction is permitted which does not comply with these terms. 